\title{
Notes on Gyromitra esculenta coll. and G. recurva, a noteworthy species of western North America
}

\author{
HARRI HARMAJA
}

\begin{abstract}
HARMAJA, H. 1979: Notes on Gyromitra esculenta coll. and G. recurva, a noteworthy species of western North America. - Karstenia 19: 46-49.

The study confirms the existence of apparently genetic variation in the size, shape, perisporium prominence, and oil drop size of the spores of what currently passes as Gyromitra esculenta (Pers.) Fr. (Pezizales: Helvellaceae). The material comprised a considerable part of the Finnish collections of $G$. esculenta and some from outside Finland. Three types of specimens, obviously representing different races or species, could be distinguished on the basis of the spore characters. One of these types apparently corresponds to the true $G$. esculenta, another to $G$. splendida Raitv. If $G$. esculenta needs to be split at the species level, several old specific epithets are available. The taxon named $G$. splendida is reported for the first time from Finland, Soviet Karelia, and North America (Michigan).

Type material of Paxina recurvum Snyder, which was recently transferred to Gyromitra Fr. as G. recurva (Snyder) Harmaja, was examined. The apothecium shape and spore characters give this species a somewhat isolated position in the genus; it is best assigned to subg. Discina (Fr.) Harmaja. G. recurva is known only from a few localities in western North America.
\end{abstract}

Harri Harmaja, Botanical Museum, University of Helsinki, Unioninkatu 44, SF00170 Helsinki 17, Finland

\section{Gyromitra esculenta}

Gyromitra esculenta (Pers.) Fr. is known to vary in a number of characters, including the degree to which the hymenium is folded, the cap margin, which usually touches the stipe but may also be loose, and the shade of colour of the hymenium and stipe. This variability appears mostly to depend on the environment or the age of the apothecium, i.e. it is not genetic. A variety with a white hymenium (var. alba Pilát 1951) and another with an orange one (var. aurantiaca Bened. 1969) may be true genetically determined taxa, but as they apparently result from one-point mutations, they should be treated as mere formae (or rather left unnamed). More significance seems to attach to the few reports on variation in spore characters. Velenovský (1934) described some new species related to $G$. esculenta (not accepted by other mycologists), separating them on, among other things, vague differences in the size and shape of the spores. Korf (1955) compared the size of the oil drops in the spores of North American and European material: 'The guttules in the spores are larger than Boudier [1905-1910] draws for this species and approache those of $G$. infula'. The most comprehensive information so far published on the spores is found in a paper by Raitviir (1974), in which he separates $G$. splendida Raitv. from $G$. esculenta mainly on the basis of some spore characters: size, shape, prominence of perisporium, and oil drop size. $G$. splendida, known only from the type specimen from Estonia, is not mentioned in the subsequent literature.

My interest in the variability of $G$. esculenta was aroused about 10 years ago when, as yet unaware of Korf's (1955) paper, I noticed that the spores of a Michigan collection differed from those I considered typical of Finnish $G$. esculenta, especially in possessing larger oil drops. Below I report the results of a preliminary study on spore variation among the collections of $\mathrm{H}$, mainly originating from Finland but with a few specimens from eastern Karelia (U.S.S.R.), Central Europe, U.S.A., and Canada. The variation reported by Korf (1955) and Raitviir (1974) was also discernible in the present material. Three fairly distinct types of specimens could be distinguished on the basis of their spores, those with the spore characters assigned to $G$. esculenta and $G$. splendida by Raitviir and a third type with spore characters somewhat intermediate between them. A 
good proportion of the herbarium specimens were immature, but when their spores were submature or mature, they could usually fairly easily be sorted among these three types, especially when a magnification of $\times 1500$ was used; the sections of hymenium were mounted in Melzer's reagent. The main features of their spores and their occurrences are as follows:

Type I (probably G. esculenta s. str.) - Spores ca. $18-23(-25) \times 10.0-12.5 \mu \mathrm{m}$ in size, most \pm ellipsoid, some subfusiform to fusiform; secondary wall (perisporium) not inflated at the spore ends or reaching ca. $0.5 \mu \mathrm{m}$ in some of them; oil drops ca. 2.5-4.5 $\mu \mathrm{m}$ in diameter. Mostly on meagre bare ground, especially sandy soil, usually near conifers, especially pines. Very common throughout Finland; a specimen from Bavaria also examined. (Fig. 1a)

Type II - Spores ca. $20-25 \times 10.0-12.5 \mu \mathrm{m}$, most subfusiform, the remainder fusiform and ellipsoid; secondary wall very slightly to fairly distinctly inflated at the ends of probably all the spores, having a width of ca. $0.3-1.0 \mu \mathrm{m}$; oil drops ca. $3.5-6.0 \mu \mathrm{m}$ in diameter. Probably generally on more fertile soil than the preceding type. Rare in South Finland; two specimens from Quebec also examined. (Fig. 1b)

Type III (? G. bubacii Vel.; G. splendida Raitv.) Spores ca. $22-30 \times 10.0-12.5 \mu \mathrm{m}$, most fusiform, the remainder subfusiform; secondary wall inflated at the ends of all the spores, having a width of ca. $0.6-1.2(-1.5) \mu \mathrm{m}$; oil drops ca. 3.5-6.0 $\mu \mathrm{m}$ in diameter. The stipe may be generally slightly longer than in the other types. Probably usually on more fertile soil than Type I. Very rare in South Finland. May prefer a continental climate. (Fig. 1c)

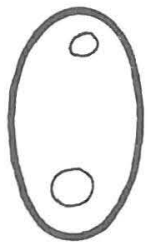

a

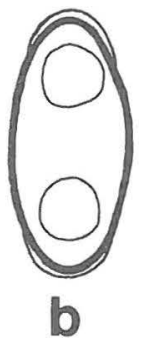

Fig. 1. Representative spores of the different types of the Gyromitra esculenta aggregate. Drawn with a camera lucida from dried material mounted in Melzer's reagent, $\times 1000$. - a) Type I (probably G. esculenta s.str.; Federal Republic of Germany, Bavaria, near Regensburg, V. 1879 Rehm, 'Ascomyceten' no. 502, H). - b) Type II (Canada, Quebec, Masham, 31.V.1963 Darker \& Shoemaker, DAOM 93064; H). - c) Type III (G. splendida; Finland, Etelä-Häme, Lammi, 22.V.1977 Harmaja; H).
Specimens examined of Type III (G. splendida Raitv.): Finland. Etelä-Häme: Hattula, 1976 Uotila (H). Lammi, 1977 Harmaja (H). U.S.S.R. Karelian A.S.S.R.: Koselma (Kotasalmi), 1863 Kullhem (H). Soukelo, 1861 Karsten (H). U.S.A. Michigan: Lupton Co., Grousehaven, 1948 Clover \& A.H. Smith $28681(\mathrm{H})$.

These types no doubt represent different, genetically controlled taxa, the morphological features described above being constant within apothecia and independent of the developmental stage of the latter (apothecia known to be long-lived, fairly large ones often still being immature; see also Kempton \& Wells 1973). However, at present it is not possible to judge whether these are separate species or only races. To answer this question, a large material should be examined, and attention should be paid to some other features whose variability also appears to be partly genetic: the shape of the cap (whether apt to be two-lobed or not), the colour of the hymenium and the stipe, the length of the stipe, the consistency of the dry apothecium, the structure of the ectal excipulum, the amount and colour of the encrustation of the paraphyses, the diameter and shape of the paraphysis tips, and the length of the terminal cells of the paraphyses. As apothecia possessing different kinds of spores are generally indistinguishable macroscopically, attention should be focused on microscopic characters.

Raitviir (1974) described the taxon discovered by him as a new species and thus introduced a new specific epithet. There are, however, surprisingly many old names usually held to be synonyms of $G$. esculenta, and these should be considered whenever $G$. esculenta is regarded as a collective species and epithets are needed for segregate species. These names include: Gyrocephalus aginnensis Pers., Gyromitra bubacii Vel., G. inflata (Cum. ex Krombh.) Cooke, G. krombholzii Bezděk, $G$. neuwirthii Vel., G. queletii Schulz., Helvella erythrophaea Pers., $H$. sinuosa Brondeau, and $H$. suspecta Krombh. The original meaning of Helvella esculenta Pers. ex Pers. is in particular need of clarification. Type material may exist for a few of the above species and can be used to examine the microscopic features, but even the remaining names should not be discarded as nomina dubia, though known only from macroscopic descriptions. Any material collected in the type locality can be analyzed microscopically, and, when only one species occurs in the locality, the origin of the name can be traced with reasonable certainty. It is thus possible that $G$. splendida Raitv. has been named validly earlier, and that this can be proved. 
The literature contains somewhat contradictory information about the toxicity of fresh apothecia of $G$. esculenta and about the effect of boiling and rinsing or of drying on the toxic constituent(s). This may be partially explained by the heterogeneity of the species: the races or species may differ in the kinds and amounts of the toxic compounds in their apothecia. Besides the true gyromitrine, Pyysalo (1975) detected related compounds. It would be interesting to know whether the composition of the gyromitrine homologues differs in the three Finnish taxa.

\section{Gyromitra recurva}

Paxina recurvum Snyder, Mycologia 28: 487. 1936. Gyromitra recurva (Snyder) Harmaja, Karstenia 18: 57. 1978. - A specimen consisting of a mixture of the paratype collection and another collection has been examined: U.S.A., Washington, Camp Mason, Lake Keechelus, on soil in deep woods, 15.IV. \& 5.V.1934 L.C. Snyder (NY).

The English part of the protologue lists two collections (Snoqualmie Pass, 14.IV.1934 and Lake Keechelus, 5.V.1934), but the Latin part mentions only 'In venta Avril, Snoqualmie Pass'. Thus the April specimen may be considered the holotype and the May collection the paratype. Provided that no confusion has taken place in labelling, the NY specimen, with a 'cotype' annotation, is thus a mixture of that paratype and a third collection, not mentioned in the protologue. Snyder's collections may also be deposited elsewhere besides NY.

The apothecia in the specimen examined have soil mixed with litter at the bases of the stipes, and some of the stipes are attached to pieces of bark. A microscopic study, mainly on sections mounted in Melzer's reagent, yielded the following results. The excipulum of the cap of the apothecium is composed throughout of textura intricata. The hyphae are distinctly inflated in places, their walls are thin, and their contents dextrinoid; cyanophilic septal collars are infrequent, being up to ca. $1.0 \mu \mathrm{m}$ broad. The asci mature at different times, their walls are inamyloid, and, when young, their contents are dextrinoid. The paraphyses are clavate, apically ca. $5.0-7.5 \mu \mathrm{m}$ in diameter, and contain abundant and conspicuous yellow-brown granules, which turn blue in thin sections well stained with cotton blue. The spores measure $11.5-13.0 \times 7.5-8.5 \mu \mathrm{m}$ and are ellipsoid. They possess a persistent, thin, apparently continuous, \pm strongly cyanophilic secondary wall (perisporium), which is verruculose throughout, with small warts of fairly uniform size (up to ca. $0.5 \mu \mathrm{m}$ high); the warts are mostly separate, being only rarely connected by very fine ridges. The secondary wall development begins at the ends of the spore in at least a proportion of the spores, but this feature is much less distinct than in all the other species of Gyromitra so far studied by me. Towards full spore maturity the secondary wall decreases somewhat in thickness between the warts; no apiculi, or inflations, are formed at the spore ends, the secondary wall thus being of uniform thickness throughout. Both the lastnamed properties appear to be infrequent in Gyromitra Fr. The spores contain distinct oil drops, mostly two large ones, which may be equal or unequal in size; a fairly considerable minority of the spores contain more than two drops, most usually three. The nuclei of the cells of the apothecium, including those of the mature spores, proved to be carminophobic (possibly weakly carminophilic in some places in the excipulum?). In young spores, however, the nuclei are weakly (and often indistinctly) carminophilic, and their number per spore was repeatedly ascertained as four. The lastmentioned character definitely proves that the species belongs to the family Helvellaceae. The anatomy of the excipulum, in particular, and the spore contents place it in Gyromitra sensu lato (sensu Harmaja 1973). All in all, the characters observed here correspond well to the protologue, except for the spore size, which was given as $14-16 \times 9-11 \mu \mathrm{m}$; however, the measurements of the spores of some other cup-fungi treated in Snyder's paper also appear too large.

Gyromitra recurva (Snyder) Harmaja is a most interesting member of Gyromitra in the broadened sense, and is identified very easily: 1) The apothecium shape is apparently unique in the genus: the stipe is distinct, slender, and \pm smooth, and meets the pileus abruptly, the pileus being \pm convex already when young, lacking distinct folds, and having a recurved margin, which is loose and far from the stipe; 2) the spores are the smallest in the genus; 3 ) it is the only species in the genus whose spores have both a rough surface (even under the light microscope) and mainly biguttulate contents. It is so far only known from western North America: from the two localities in western Washington mentioned in the protologue, and from British Columbia, Oregon, and Idaho (Larsen \& Denison 1978).

The characters of this species provide further proof of the arbitrary nature of the genus Discina (Fr.) Fr. (sensu Eckblad 1968): G. recurva shows that a rough spore surface is not always combined with 1- or 3guttulate spore contents. However, I consider it possible to accept the Discina-Neogyromitra group at the subgeneric level, as Gyromitra subg. Discina (Fr.) 
Harmaja. G. recurva is best placed in this subgenus. G. melaleuca (Bres.) Donad. (Donadini [1975] made this combination slightly earlier than I myself, 1976) is another member of Gyromitra whose spores have a variable number of oil drops, but in that species the predominant number is apparently three.

Acknowledgement. Prof. Clark T. Rogerson, New York (NY), kindly arranged the loan of type material of Paxina recurvum for my study.

\section{References}

Benedix, E.H. 1969: Art- und Gattungsgrenzen bei höheren Discomyceten 3. - Kulturpflanze 17: 253-284.

Boudier, E. 1905-1910: Icones mycologicae. - 4 vols. Paris.

Donadini, J.C. 1975: Discomycètes operculés de Provence. - Bull. Soc. Linn. Provence 28: 69-92.

Eckblad, F.-E. 1968: The genera of the operculate Discomycetes. A re-evaluation of their taxonomy, phylogeny and nomenclature. - Nytt Mag.Bot. 15: $1-191$.

Harmaja, H. 1973: Amendments of the limits of the genera Gyromitra and Pseudorhizina, with the description of a new species, Gyromitra montana. - Karstenia 13: $48-58$.

_'- 1976: Paradiscina Benedix - a synonym of Gyromitra Fr. - Karstenia 15: 33-35.

Kempton, P.E. \& Wells, V.L. 1973: Studies on the fleshy fungi of Alaska 6. Notes on Gyromitra. - Mycologia 65: $396-400$.

Korf, R.P. 1955: Discomyceteae exsiccatae, Fasc. I. Mycologia 46: 837-841.

Larsen, H.J. Jr. \& Denison, W.C. 1978: A checklist of the operculate cup-fungi (Pezizales) of North America west of the Great Plains. - Mycotaxon 7: 68-90.

Pilát, A. 1951: Hymenomycetes novi vel minus cogniti Cechoslovakiae. - Stud. Bot. Cechoslovaca 12: 1-72.

Pyysalo, H. 1975: Some new toxic compounds in false morels, Gyromitra esculenta. - Naturwissensch. 62: 395.

Raitviir, A. 1974: A new species of Gyromitra from Estonia. - Fol. Crypt. Estonica 4: 30-31.

Velenovský, J. 1934: Monographia Discomycetum Bohemiae 1-2. - $436 \mathrm{pp}, 31$ pls. Praha.

Accepted for publication

on October 2, 1978 